\title{
Comparison of raw and processed Radix Polygoni Multiflori (Heshouwu) by high performance liquid chromatography and mass spectrometry
}

\author{
Zhitao Liang, Hubiao Chen, Zhiling Yu, Zhongzhen Zhao*
}

\begin{abstract}
Background: Radix Polygoni Multiflori is the dried root tuber of Polygonum multiflorum Thunb. (Fam. Polygonaceae). According to Chinese medicine theory, raw (R-RPM) and processed (P-RPM) Radix Polygoni Multiflori possess different properties. The present study investigates the differences in chemistry between raw and processed Radix Polygoni Multiflori.

Methods: Five pairs of R-RPM and P-RPM as well as 15 commercial decoction pieces were analyzed with high performance liquid chromatography (HPLC) and mass spectrometry (MS).

Results: Two anthraquinones, namely emodin-8-O-(6'-O-malonyl)-glucoside and physcion-8-O-(6'-O-malonyl)glucoside disappeared or decreased significantly and 2,3,5,4'-tetrahydroxystilbene-2-O- $\beta$-D-glucopyranoside, emodin-8-O- $\beta$-D-glucopyranoside and physcion-8-O- $\beta$-D-glucopyranoside decreased after the R-RPM samples being processed. On the other hand, the contents of emodin and physcion generally increased after processing.

Conclusion: The present study indicates that processing Radix Polygoni Multiflori may change the contents and types of chemicals in it. These changes are probably responsible for the various pharmacological effects of R-RPM and P-RPM as well as hepatotoxicity.
\end{abstract}

\section{Background}

Proper pharmaceutical processing may reduce toxicity or side effects, potentiate the beneficial effects, change the pharmacological properties, preserve active constituents, facilitate administration, improve flavor or correct unpleasant taste and increase purity of Chinese materia medica [1-4]. In China, the processing methods for Radix Polygoni Multiflori have been practiced since the Tang dynasty [5] and are documented in the Chinese pharmacopoeia [6]. Radix Polygoni Multiflori (Heshouwu) is the dried root tuber of Polygonum multiflorum Thunb. (Fam. Polygonaceae) [6]. According to Chinese medicine theory, raw Radix Polygoni Multiflori (R-RPM) counteracts toxicity, cures carbuncles and relaxes the bowels whereas processed Radix Polygoni Multiflori (P-RPM) replenishes the liver and kidney with

\footnotetext{
* Correspondence: zzzhao@hkbu.edu.hk

School of Chinese Medicine, Hong Kong Baptist University, Kowloon, Hong Kong SAR, China
}

(c) 2010 Liang et al; licensee BioMed Central Ltd. This is an Open Access article distributed under the terms of the Creative Commons Attribution License (http://creativecommons.org/licenses/by/2.0), which permits unrestricted use, distribution, and reproduction in any medium, provided the original work is properly cited. vital essence and blood, blackens the hair and strengthens the tendons and bones.

R-RPM and P-RPM possess different pharmacological properties. While P-RPM (steamed with black bean juice) enhanced immune activities and anti-immunosuppression, R-RPM did not [7]. R-RPM was purgative whereas P-RPM was not [8], probably due to lower content of anthraquinones glycosides in P-RPM. R-RPM inhibited triglyceride accumulation induced by carbon tetrachloride $\left(\mathrm{CCl}_{4}\right)$, cortisone acetate and thioacetamide (TAA) in the mouse liver and P-RPM lowered the triglyceride accumulation induced by cortisone acetate; both R-RPM and P-RPM reduced liver enlargement caused by $\mathrm{CCl}_{4}[9]$.

It is important to differentiate R-RPM from P-RPM because Radix Polygoni Multiflori was linked to hepatotoxicity and other liver conditions [10-15]. Over-thecounter preparations such as Shouwu pian and Shenmin (both containing Radix Polygoni Multiflori) may cause acute hepatitis. A recent study found that, Radix Polygoni Multiflori was the hepatotoxic component that 
caused acute hepatitis [16]. There were other hepatotoxic cases related to Radix Polygoni Multiflori [17-20]. R-RPM did not induce liver injury [21] but P-RPM could damage rat's liver after long-term use of high dosages $(40 \mathrm{~g} / \mathrm{kg} /$ day $)$ by intragastric administration. However, no toxic or side effects were found when P-RPM was used at the dosage of $22 \mathrm{~g} / \mathrm{kg} /$ day which is 10 times of the normal intake for adult per day [22,23].

Radix Polygoni Multiflori contains anthraquinones (emodin, chrysophanol, physcion, citreorosein, chrysophanol-8-O- $\beta-D$ - glucopyranoside, physcion-8-O- $\beta-D-$ glucopyranoside, emodin-8-O- $\beta$ - $D$ - glucopyranoside, emodin-1,6-dimethylether, questin, questinol, 2 -acetylemodin, 2-methoxy-6-acetyl-7-methyljuglone, emodin-8$O$-(6'-O-malonyl)-glucoside) [24-26]; stilbene glucosides (2,3,5,4'-tetrahydroxystilbene-2- $O-\beta$ - $D$-glucopyranoside, $2,3,5,4$ '- tetrahydroxystilbene- $2,3-O-\beta-D$ - glucopyranoside [27]) and flavonoids (tricin [25], quercetin-3-Ogalactoside, quercetin-3-O-arabinoside [28]), as well as gallic acid, catechin [29], torachrysone-8-O- $\beta$ - $D$-glucopyranoside [27], $\mathrm{N}$-transferuloyl tyramine, $\mathrm{N}$-transferuloyl-3-methyldopamine [25] and 1,3-dihydroxy-6,7 -dimethylxanthone -1-O- $\beta-D$-glucopyranoside [27]. There were more free anthraquinones in P-RPM than that in R-RPM. However, anthraquinone glycosides and stilbene glucoside were more abundant in R-RPM than P-RPM [30]. P-RPM contains components not present in R-RPM, namely 2,3-dihydro-3,5-dihydroxy-6-methyl-4 $(\mathrm{H})$-pyran-4-one and 5-hydroxymethyl furfural; P-RPM contains less amino acids and monosaccharides and has a lower $\mathrm{pH}$ value than R-RPM [31].

In recent years, high performance liquid chromatography (HPLC) and gas chromatography (GC) have been employed to determine the level of anthraquinones in Radix Polygoni Multiflori [32,33].

Using HPLC-DAD and mass spectrometry, the present study compares five pairs of raw and processed Radix Polygoni Multiflori as well as some samples from commercially available decoctions.

\section{Methods}

Plants

Five samples of R-RPM and 15 samples of commercial decoction pieces of Radix Polygoni Multiflori were collected from cultivation areas or purchased from pharmacies in China (Table 1). The R-RPM was softened by water and then steamed in an autoclave (HV-85, Hirayama, Japan) for four hours at $121 \square$ and under 2.03 pounds per square inch (psi), according to the processing methods documented in the Chinese pharmacopoeia [6].

Table 1 A list of tested samples from China

\begin{tabular}{|c|c|c|c|}
\hline Sample name & No. & Source & $\begin{array}{l}\text { Collection } \\
\text { time }\end{array}$ \\
\hline \multirow[t]{5}{*}{ Raw Radix Polygoni Multiflori } & 1 & $\begin{array}{l}\text { Daqiao Village, Deqing County, Guangdong, China; } \\
\text { cultivated }\end{array}$ & 2008. 05. 30 \\
\hline & 2 & $\begin{array}{l}\text { Dengyun Village, Deqing County, Guangdong, China; } \\
\text { cultivated }\end{array}$ & 2008. 05. 30 \\
\hline & 3 & $\begin{array}{l}\text { Duimian Village, Deqing County, Guangdong, China; } \\
\text { cultivated }\end{array}$ & 2008. 05. 30 \\
\hline & 4 & Chengdu, Sichuan, China; market & 2008. 09. 25 \\
\hline & 5 & Guangzhou, Guangdong, China; market & 2008. 12. 10 \\
\hline \multirow{8}{*}{$\begin{array}{l}\text { Commercial Radix Polygoni Multiflori from Deqing County, } \\
\text { Guangdong, China }\end{array}$} & 1 & Wild & 2007. 12. 25 \\
\hline & 2 & Half wild for $5-6$ years & 2007. 12. 25 \\
\hline & 3 & Cultivated in the mountain for $5-6$ years & 2007. 12. 25 \\
\hline & 4 & Cultivated in the normal soil for 3-4 years & 2007. 12. 25 \\
\hline & 5 & Cultivated in the mountain & 2007. 12. 25 \\
\hline & 6 & Cultivated in the normal soil for one year & 2007. 12. 25 \\
\hline & 7 & Cultivated in the normal soil for one year & 2007. 12. 25 \\
\hline & 8 & Cultivated in the normal soil for one year & 2007. 12. 25 \\
\hline \multirow{7}{*}{$\begin{array}{l}\text { Commercial processed Radix Polygoni Multiflori from Chinese herbal } \\
\text { shops }\end{array}$} & 1 & Hong Kong, China; market & 2007. 12. 05 \\
\hline & 2 & Hong Kong, China; market & 2007. 12. 05 \\
\hline & 3 & Hong Kong, China; market & 2007. 12. 05 \\
\hline & 4 & Hong Kong, China; market & 2007. 12. 05 \\
\hline & 5 & Shenzhen, Guangdong, China; market & 2007. 12. 05 \\
\hline & 6 & Shenzhen, Guangdong, China; market & 2007. 12. 05 \\
\hline & 7 & Guangzhou, Guangdong, China; market & 2008. 12. 10 \\
\hline
\end{tabular}




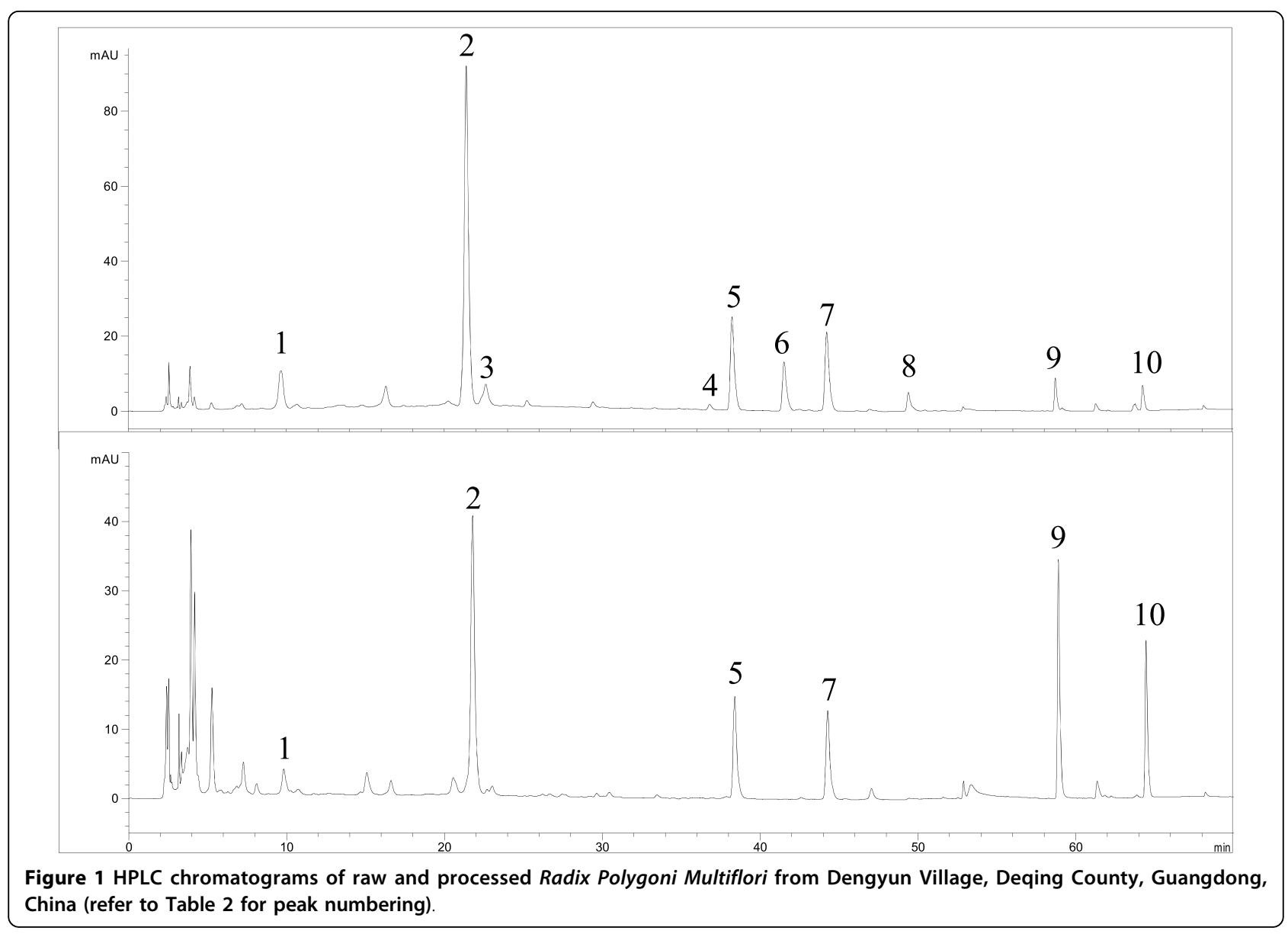

All the herbs were authenticated macroscopically by Prof Zhongzhen Zhao. The corresponding voucher specimens were deposited in the Bank of China (Hong Kong) Chinese Medicines Centre of Hong Kong Baptist University, Hong Kong SAR, China.

\section{Instrumentation}

A CREST 1875HTAG ultrasonic processor (CREST, USA) was used for sample extraction. HPLC fingerprinting analysis was performed on an Agilent1100 series LC system consisting of a G1311A Quart pump, a G1322A degasser, a G1315A photodiode array detector (DAD) and a G1313A automatic liquid sampler (ALS). A MicroQTOF system with an electrospray ionization source (Bruker Daltonics, Germany) was used for mass spectrometric analysis. Separation was performed at room temperature on an Alltima $\mathrm{C}_{18}$ analytical column (250 $\mathrm{mm} \times 4.6 \mathrm{~mm}, 5 \mu \mathrm{m}$, Alltech Associates, USA) coupled with a $\mathrm{C}_{18}$ guard column $(7.5 \mathrm{~mm} \times 4.6 \mathrm{~mm}, 5$ $\mu \mathrm{m}$, Alltech Associates, USA) that was eluted with acetonitrile (containing $0.5 \%$ acetic acid)/water (containing $0.5 \%$ acetic acid) at a flow rate of $1 \mathrm{~mL} / \mathrm{min}$ by a discontinuous gradient in which acetonitrile was adjusted to $10 \%, 35 \%$ and $100 \%$, at 0,45 and 65 minutes respectively. Detection was performed at $280 \mathrm{~nm}$. The mass spectra were detected in positive mode. The flow rate of drying gas $\left(\mathrm{N}_{2}\right)$ and nebulizing gas were $4 \mathrm{~L} / \mathrm{min}$ and $0.4 \mathrm{~L} / \mathrm{min}$ respectively. Ion source temperature was set at $200 \square$ and the scan range was 200-1500 amu.

\section{Chemicals and reagents}

HPLC-grade acetonitrile (Labscan, Thailand) and deionized water obtained from a Milli-Q water system (Millipore, USA) were used for preparation of the mobile phase. Analytical grade methanol (Labscan, Thailand) was used for preparation of standards and sample extraction. Reference compounds of 2,3,5,4'-tetrahydroxystilbene-2-O- $\beta$ - $D$ - glucopyranoside (THSG, 1), emodin (2) and physcion (3) (purities $>97 \%$ ) were purchased from the National Institute for the Control of Pharmaceutical and Biological Products, China (Batch numbers 110844200505, 110756-200110 and 110758-200610 respectively).

\section{Preparation of standard and sample solutions}

The three reference compounds (1-3) were accurately weighed and dissolved in methanol to produce standard 

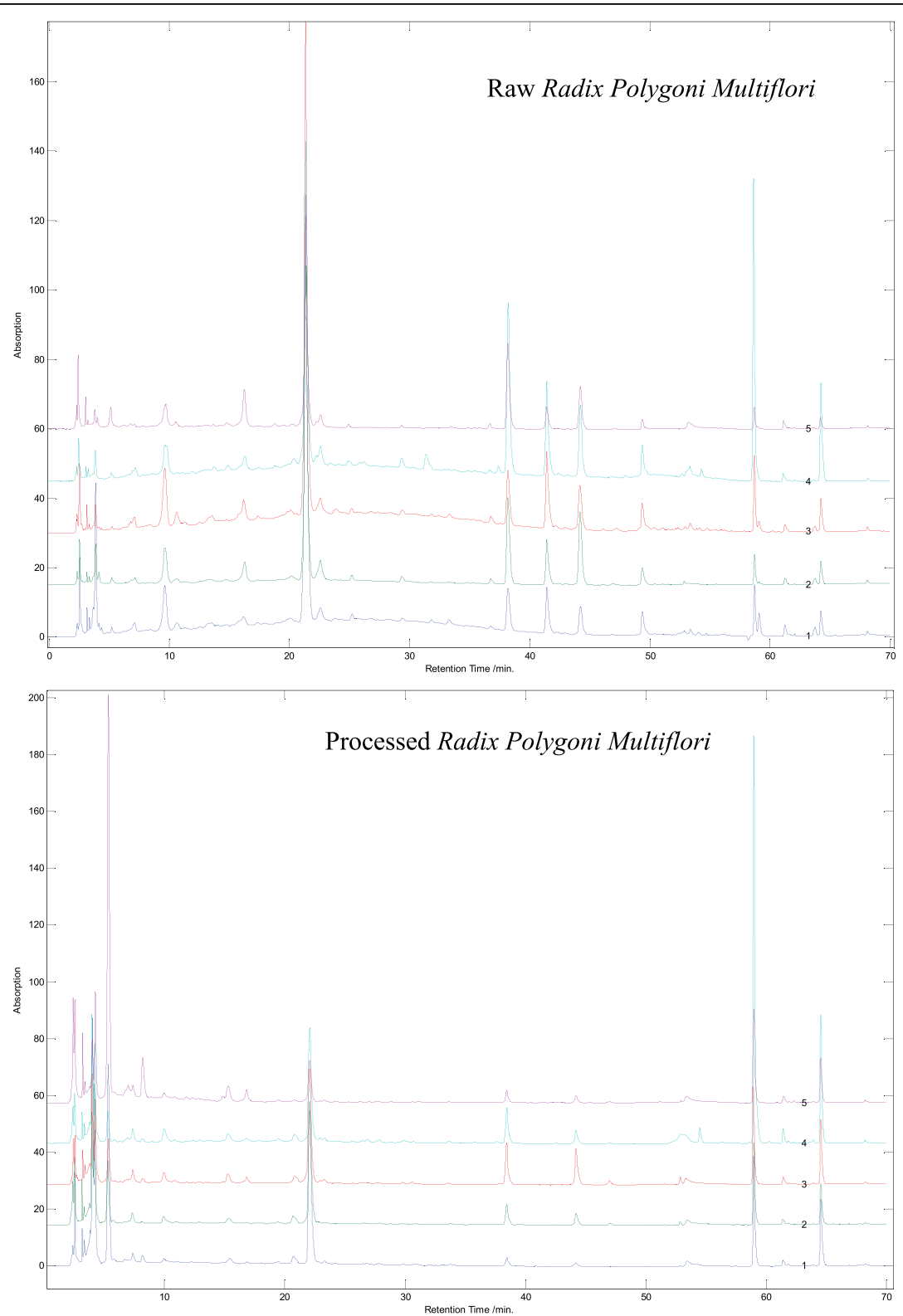

Figure 2 HPLC fingerprints of R-RPM and its corresponding P-RPM from various sources in China.

Table 2 MS data of major identified/unknown compounds in the HPLC chromatograms of R-RPM

\begin{tabular}{|c|c|c|}
\hline Peak No. & Mass Spectra & Identified compounds (tentative names) \\
\hline 1 & $291.1\left([\mathrm{M}+\mathrm{H}]^{+}\right) ; 581.2\left([2 \mathrm{M}+\mathrm{H}]^{+}\right)$ & Catechin \\
\hline 2 & $407.1\left([\mathrm{M}+\mathrm{H}]^{+}\right)$ & $2,3,5,4^{\prime}$-tetrahydroxystilbene-2-O- $\beta$-D- glucopyranoside \\
\hline 3 & $257.1\left([\mathrm{M}+\mathrm{H}-\mathrm{glu}]^{+}\right) ; 419.1\left([\mathrm{M}+\mathrm{H}]^{+}\right)$ & 1,3-dihydroxy-6,7-dimethylxanthone-1- $0-\beta$-D- glucopyranoside \\
\hline 4 & $247.1\left([\mathrm{M}+\mathrm{H}-\mathrm{glu}]^{+}\right) ; 409.1\left([\mathrm{M}+\mathrm{H}]^{+}\right) ; 431.1\left([\mathrm{M}+\mathrm{Na}]^{+}\right)$ & Torachrysone-8- $O-\beta$ - $D$ - glucopyranoside \\
\hline 5 & $271.1\left([\mathrm{M}+\mathrm{H}-\mathrm{glu}]^{+}\right) ; 455.1\left([\mathrm{M}+\mathrm{Na}]^{+}\right)$ & Emodin-8-O- $\beta$-D-glucopyranoside \\
\hline 6 & $271.1\left([\mathrm{M}+\mathrm{H}-\mathrm{malonyl}-\mathrm{glu}]^{+}\right) ; 541.1\left([\mathrm{M}+\mathrm{Na}]^{+}\right) ; 1059.2\left([2 \mathrm{M}+\mathrm{K}]^{+}\right)$ & Emodin-8-(6'-O-malonyl)-glucoside \\
\hline 7 & $285.1\left([\mathrm{M}+\mathrm{H}-\mathrm{glu}]^{+}\right) ; 469.1\left([\mathrm{M}+\mathrm{Na}]^{+}\right)$ & Physcion-8-O- $\beta$-D- glucopyranoside \\
\hline 8 & $285.1\left([\mathrm{M}+\mathrm{H}-\mathrm{malonyl}-\mathrm{glu}]^{+}\right) ; 555.1\left([\mathrm{M}+\mathrm{Na}]^{+}\right) ; 1103.2\left([2 \mathrm{M}+\mathrm{K}]^{+}\right)$ & Physcion-8-O-(6'-O-malonyl)-glucoside \\
\hline 9 & $271.1\left([\mathrm{M}+\mathrm{H}]^{+}\right)$ & Emodin \\
\hline 10 & $285.1\left([\mathrm{M}+\mathrm{H}]^{+}\right)$ & Physcion \\
\hline
\end{tabular}




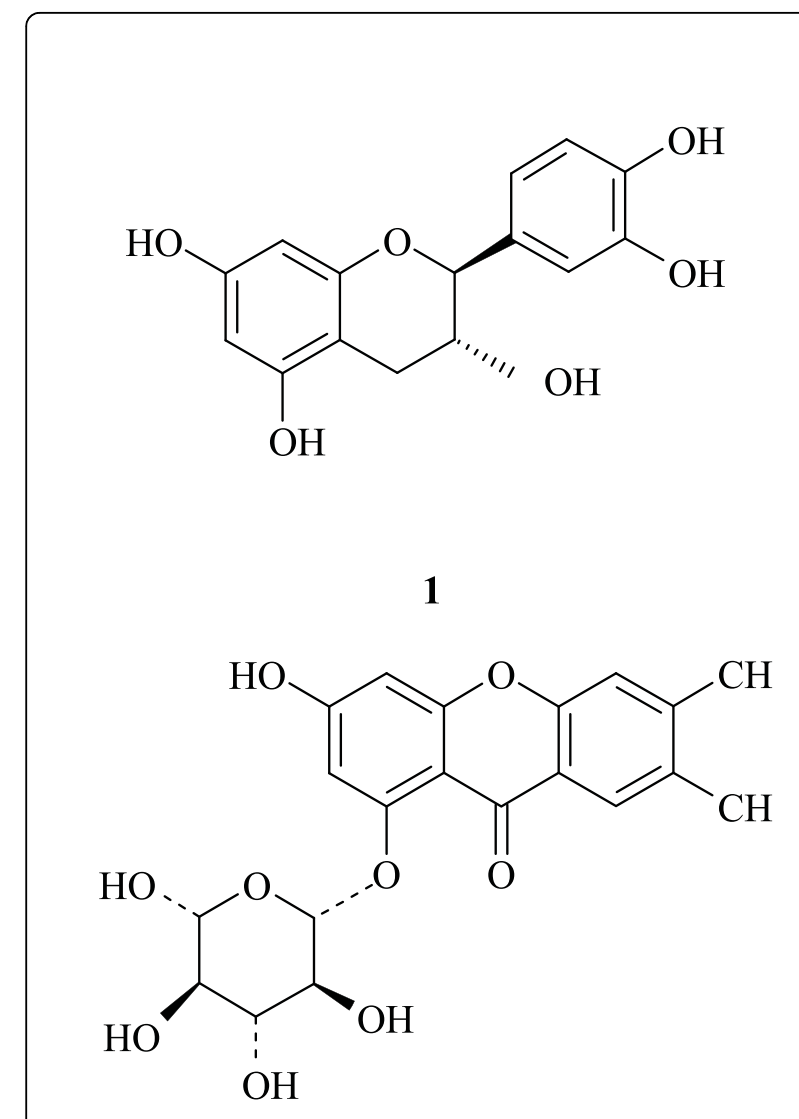

3<smiles>OC[C@H]1O[C@@H](Oc2c(O)cc(O)cc2/C=C/c2ccc(O)cc2)[C@H](O)[C@H](O)[C@@H]1O</smiles>

2

4<smiles>[R2]c1cc(O)c2c(c1)Cc1cc([R2])cc(O)c1C2=O</smiles>

$5 \quad \mathrm{R}_{1}=\mathrm{CH}_{3} ; \mathrm{R}_{2}=\mathrm{OH} ; \mathrm{R}_{3}=\mathrm{Glc}$

$6 \mathrm{R}_{1}=\mathrm{CH}_{3} ; \mathrm{R}_{2}=\mathrm{OH} ; \mathrm{R}_{3}=\left(6^{\prime}\right.$-malonyl $)-\mathrm{Glc}$

$7 \quad \mathrm{R}_{1}=\mathrm{CH}_{3} ; \mathrm{R}_{2}=\mathrm{OCH}_{3} ; \mathrm{R}_{3}=\mathrm{Glc}$

$8 \mathrm{R}_{1}=\mathrm{CH}_{3} ; \mathrm{R}_{2}=\mathrm{OCH}_{3} ; \mathrm{R}_{3}=\left(6^{\prime}\right.$-malonyl $)$-Glc

$9 \mathrm{R}_{1}=\mathrm{CH}_{3} ; \mathrm{R}_{2}=\mathrm{OH} ; \mathrm{R}_{3}=\mathrm{H}$

$10 \mathrm{R}_{1}=\mathrm{CH}_{3} ; \mathrm{R}_{2}=\mathrm{OCH}_{3} ; \mathrm{R}_{3}=\mathrm{H}$

Note:<smiles>[14CH2]=CC(=O)CC(=O)O</smiles>

Figure 3 Chemical structures of the identified compounds in the HPLC chromatograms Peak 1: catechin; Peak 2: 2,3,5,4'tetrahydroxystilbene-2-O- $\beta$-D- glucopyranoside; Peak 3: 1,3-dihydroxy-6,7-dimethylxanthone-1-O- $\beta$ - $D$-glucopyranoside; Peak 4: torachrysone-8-O- $\beta$-D-glucopyranoside; Peak 5: emodin-8-O- $\beta$ - $D$ - glucopyranoside; Peak 6: emodin-8-(6'-O-malonyl)-glucoside; Peak 7: physcion-8-O- $\beta$-D- glucopyranoside; Peak 8: physcion-8-O-(6'-O- malonyl)-glucoside; Peak 9: emodin; Peak 10: physcion. 


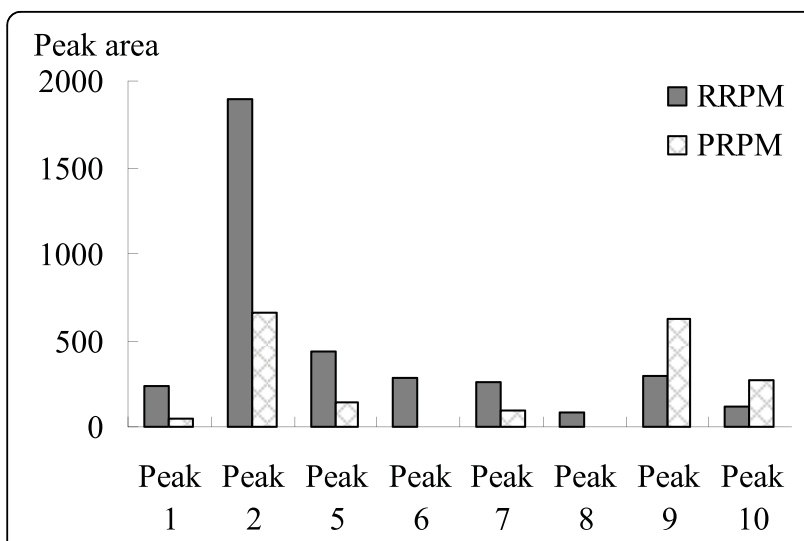

Figure 4 The change of relative contents of main compounds between R-RPM and their corresponding P-RPM.

solutions. $0.5 \mathrm{~g}$ powdered sample was refluxed with $25 \mathrm{ml}$ methanol for 90 minutes. Then the supernatant was filtered through a $0.45 \mu \mathrm{m}$ membrane and $10 \mu \mathrm{l}$ samples were analyzed with HPLC and LC-MS.

\section{Method validation}

Reproducibility and repeatability of the method were determined with five injections of one sample solution and five replicates of one solid sample prepared according to the method. Stability of the method was determined with the sample solution after $0,2,4,8$ and 12 hours in a single day and for further one and two days.

\section{Data processing}

Chromatographic data were analyzed with Computer Aided Similarity Evaluation System software (Central South University, China) [34]. The software synchronized the chromatographic peaks and calculated the correlation coefficients for similarity of the chromatograms.

\section{Results and discussion}

Optimization and validation of HPLC conditions

To optimize the elution conditions, we investigated the mobile phase of acetonitrile (containing $0.5 \%$ acetic acid)-water (containing $0.5 \%$ acetic acid) with various gradients and the optimal acetonitrile-water system was determined to have acetonitrile adjusted to $10 \%, 35 \%$, and $100 \%$, at 0,45 and $65 \mathrm{~min}$, respectively.

The limits of detection, evaluated by a signal-tonoise ratio of about $3: 1$ for the standard solution, were $0.575 \mu \mathrm{g} / \mathrm{ml}, 0.343 \mu \mathrm{g} / \mathrm{ml}$ and $0.523 \mu \mathrm{g} / \mathrm{ml}$ for compounds 1, 2 and 3 respectively. The correlation coefficients were $0.973 \pm 0.021(n=5)$ at $280 \mathrm{~nm}$ detection wavelength for reproducibility and $0.968 \pm$ $0.022(n=5)$ for repeatability test. In stability testing, the correlation coefficients were $0.972 \pm 0.034(n=5)$ over a period of 12 hours and $0.984 \pm 0.015(n=7)$ over a period of three days. These results indicated that the conditions for the fingerprint analysis were satisfactory.

\section{Comparison of R-RPM and P-RPM fingerprints}

Five samples of R-RPM and their corresponding P-RPM were analyzed. Chromatograms for R-RPM and P-RPM were visually distinguishable from each other (Figures 1 and 2). In the chromatograms of R-RPM, there were ten well-separated chromatographic peaks (Figure 1). Chromatographic peaks 2, 9 and 10 were unambiguously identified as $2,3,5,4^{\prime}$-tetrahydroxystilbene-2-O- $\beta$ - $D$ glucopyranoside (THSG), emodin and physcion

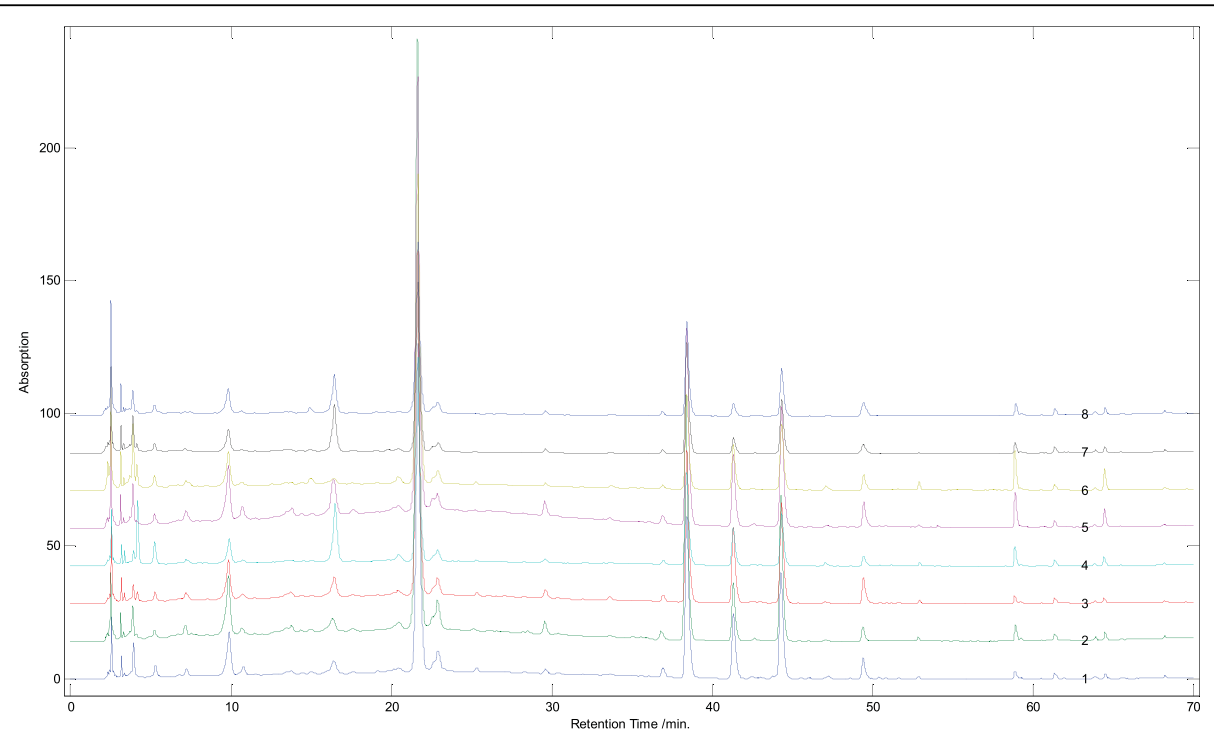

Figure 5 HPLC fingerprints of commercial decoction pieces of Radix Polygoni Multiflori from Deqing County, Guangdong, China. 


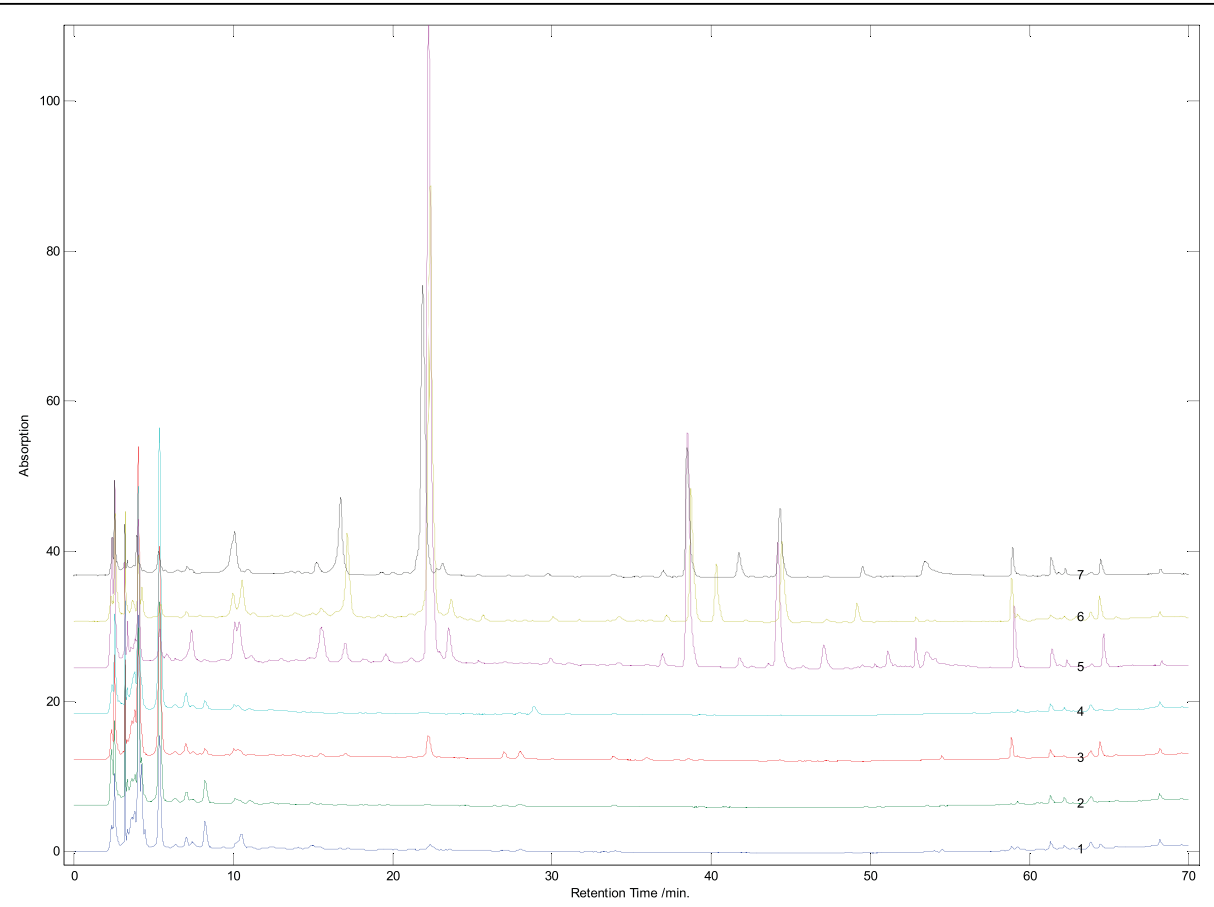

Figure 6 HPLC fingerprints of commercial P-RPM purchased from Chinese herb shops in Hong Kong, Shenzhen and Guangzhou.

respectively. Chromatographic peaks $1,3,4,5,6,7$ and 8 were tentatively identified as catechin, 1,3 -dihydroxy6,7-dimethylxanthone- $1-O-\beta$-D-glucopyranoside, torachrysone-8-O- $\beta$ - $D$-glucopyranoside, emodin-8-O- $\beta$ $D$ - glucopyranoside, emodin-8-(6'-O-malonyl)-glucoside, physcion-8-O- $\beta$ - $D$ - glucopyranoside and physcion-8-O(6'-O- malonyl)-glucoside [26,27,29]. The exact cis/trans configuration of catechin was not identified. Moreover, physcion-8-O-(6'-O-malonyl)-glucoside was identified in R-RPM for the first time (Table 2 and Figure 3).

The chromatograms of R-RPM showed that catechin, THSG and anthraquinones glycosides were the main components. The concentrations of these constituents decreased greatly after being processed. Emodin-8-O-(6'$O$-malonyl)-glucoside and physcion-8-O-(6'-O-malonyl)glucoside disappeared or decreased greatly in the processed products (Figures 1 and 2). Meanwhile, catechin, THSG, emodin-8-O- $\beta$ - $D$-glucopyranoside and physcion8-O- $\beta$ - $D$-glucopyranoside decreased among five of the tested samples (Figure 4). On the other hand, the contents of emodin and physcion increased on average. The change of emodin-8-O-(6'-O-malonyl)-glucoside, physcion-8-O-(6'-O-malonyl)-glucoside, emodin-8-O- $\beta$ - $D$ glucopyranoside and physcion-8- $O-\beta$ - $D$-glucopyranoside probably contributed to the increase of emodin and physcion. The results indicated that heating made anthraquinones glycosides lose their glycosides and that the ratio of free anthraquinones to anthraquinones glycosides increased greatly while the ratio of THSG to free anthraquinones decreased. The change in type, amount and ratio of chemical components is probably responsible for the different functions and pharmacological effects of R-RPM and P-RPM.

\section{Comparison of fingerprints of commercial Radix Polygoni Multiflori}

In Deqing County, Guangdong, China (considered genuine production area for Radix Polygoni Multiflori), we purchased several grades of commercial decoction pieces of Radix Polygoni Multiflori at the local herb markets (Table 1). The correlation coefficients for the fingerprints were $0.978 \pm 0.012(n=8)$, suggesting that the samples were very similar among them (Figure 5). We further compared seven batches of samples purchased from pharmacies in Hong Kong, Shenzhen and Guangzhou. Unfortunately, the correlation coefficients were $0.671 \pm 0.116(n=8)$, suggesting that the samples varied significantly in both content and chemicals among these P-RPM samples (Figure 6). For example, the samples from Hong Kong were over-processed, drastically reducing the content of THSG, emodin-8-O-(6'-O-malonyl)glucoside and physcion-8-O-(6'-O-malonyl)-glucoside which were present in all the samples from Shenzhen and Guangzhou.

\section{Conclusion}

The present study demonstrates that processing Radix Polygoni Multiflori may change the contents, 
particularly the quantity and types of chemicals in it. These changes are probably responsible for the various pharmacological effects of R-RPM and P-RPM as well as hepatotoxicity.

We report here for the first time the disappearance or significant decrease of the two glucosides, emodin8-O-(6'-O-malonyl)-glucoside and physcion-8-O-(6'-Omalonyl)-glucoside, during the processing of R-RPM. These two compounds may be used as chemical markers for differentiating R-RPM from P-RPM. In addition, these two compounds together with emodin-8-O$\beta$ - $D$-glucopyranoside, physcion-8- $O-\beta$ - $D$-glucopyranoside, emodin and physcion may be used as chemical markers for the quality control of R-RPM; the latter four compounds may be used to assess the quality of P-RPM.

\begin{abstract}
Abbreviations
R-RPM: raw Radix Polygoni Multiflori; P-RPM: processed Radix Polygoni Multiflori; HPLC: high performance liquid chromatography; MS: mass spectrometry; THSG: 2,3,5,4'-tetrahydroxystillbene-2-O- $\beta$-D-glucopyranoside
\end{abstract}

\section{Acknowledgements}

The project was supported by the Faculty Research Grant of Hong Kong Baptist University (FRG/08-09/035).

\section{Authors' contributions}

$\mathrm{ZY}$ and $\mathrm{HC}$ designed the study. ZL conducted the experiments and drafted the manuscript. ZZ supervised the study and revised the manuscript. All authors read and approved the final version of the manuscript.

\section{Competing interests}

The authors declare that they have no competing interests.

Received: 30 March 2010 Accepted: 12 August 2010

Published: 12 August 2010

\section{References}

1. Zhu YP: Chinese Materia Medica: Chemistry, Pharmacology and Applications. Amsterdam: Harwood Medicine Association 1998.

2. $L i X G$, Fu L, Lu Q, Li X: Study on hydrolysis reaction of ginsenoside and products in red ginseng processing. J Jilin Agric Univ 2000, 22:1-9.

3. Cai BC, Nagasawa T, Kadota S, Hattori M, Namba T, Kuraishi Y: Processing of nux vomica VII. Antinociceptive effects of crude alkaloids from the processed and unprocessed seeds of Strychnos nux-vomica in mice. Biol Pharm Bull 1996, 19:127-131.

4. Cai BC, Chen L, Kadota S, Hattori M, Namba T: Processing of nux vomica IV. A comparison of cytotoxicity of nine alkaloids from processed seeds of Strychnos nux vomica on tumor cell lines. Nat Med 1995, 49:39-42.

5. Chen Y: Study on the relativity of processing level and inner quality of Radix Polygoni Multiflori. Master thesis Beijing University of Traditional Chinese Medicine, School of Traditional Chinese Materia Medica 2004.

6. Pharmacopoeia Commission of People's Republic of China: Heshouwu. Pharmacopoeia of the People's Republic of China Beijing: Chemical Industry Press 2005, 122.

7. Ye DJ, Zhu Q, Qi HL, Xie JM: Immunopharmacological study on raw Radix Polygoni Multiflori and its processed products. Zhongyao Tongbao 1987, 12:21-24.

8. Zhao RH, Zhao SL, Mao XJ, Jie FJ, Liu ZZ: Study on the correlation ship between the content of combined anthraquinone and purgative action of steamed Polygonum multiflorum Thunb. Lishizhen Med Mat Med Res 2008, 19:2654-2655.
9. Liu CJ, Zhang QH, Lin J: Effect of the root of Polygonum multiflorum Thunb. and its processed products on fat accumulation in the liver of mice. Zhongguo Zhong Yao Za Zhi 1992, 17:595-596.

10. But PPH, Tomlinson B, Lee KL: Hepatitis related to the Chinese medicine Shou-wu-pian manufactured from Polygonum multiflorum. Vet Hum Toxicol 1996, 38:280-282.

11. Park GJH, Mann SP, Ngu MC: Acute hepatitis induced by Shou-Wu-Pian, a herbal product derived from Polygonum multiflorum. J Gastroenterol Hepatol 2001, 16:115-117.

12. Mazzanti G, Battinelli L, Daniele C, Mastroianni CM, Lichtner M, Coletta S, Costantini S: New case of acute hepatitis following the consumption of Shou Wu Pian, a Chinese herbal product derived from Polygonum multiflorum. Ann Intern Med 2004, 140:W30.

13. Panis B, Wong DR, Hooymans PM, De Smet PA, Rosias PP: Recurrent toxic hepatitis in a Caucasian girl related to the use of Shou-Wu-Pian, a Chinese herbal preparation. J Pediatr Gastroenterol Nutr 2005, 41:256-258.

14. Cárdenas A, Restrepo JC, Sierra F, Correa G: Acute hepatitis due to shenmin: a herbal product derived from Polygonum multiflorum. I Clin Gastroenterol 2006, 40:629-632.

15. Yuen MF, Tam S, Fung J, Wong DK, Wong BC, Lai CL: Traditional Chinese medicine causing hepatotoxicity in patients with chronic hepatitis $B$ infection: a 1-year prospective study. Aliment Pharmacol Ther 2006, 24:1179-1186.

16. Laird AR, Ramchandani N, deGoma EM, Avula B, Khan IA, Gesundheit N: Acute hepatitis associated with the use of an herbal supplement mimicking iron-overload syndrome. J Clin Gastroenterol 2008, 42:861-862.

17. Ye QH: A case report about acute toxic hepatopathy induced by Radix Polygoni Multiflori. Chin J Integ Trad West Med 1996, 16:732.

18. Sheng JQ: Familial injury induced by Radix Polygoni Multiflori. Chin J Hepatol 1998, 6:59.

19. Zhang $X$, Ding XC: Six cases' report about liver injury induced by Radix Polygoni Multiflori. J Ningxia Med Coll 2000, 22:116.

20. Yang DQ: Heshouwu-related several liver impairment. Adv Drug React J 2005, 6:449.

21. Liu YD, Huang XX, Wu LS, Sun DM, Lu DY: Hepatotoxic experimental research on Radix Polygoni Multiflori. J Asia Pac Trad Med 2007, 4:71-72.

22. Hu XQ, Fang HL, Quan ZB, Geng ZY: Experimental study of Radix Polygoni Multiflori preparata on liver's biochemical matters. J Shaanxi Coll Trad Chin Med 2007, 30:63-64

23. Hu XQ, Yang HL, Zhang XQ, Miao YX, Geng ZY: Experimental study on the toxicology of prepared Radix Polygoni Multiflori to the rats' liver. J Shaanxi Coll Trad Chin Med 2006, 29:40-41

24. Yang XW, Gu ZM, Ma CM, Masao H, Tsuneo N: A new indole derivate from Polygonum multiflorum Thunb. Zhongcaoyao 1998, 29:5-11.

25. Li JB, Lin M: The study on the constituents of the roots of Polygonum multiflorum Thunb. Zhongcaoyao 1993, 24:115-118.

26. Zhang ZG, Lu TS, Yao QQ: Study on the anthraquinone components of the roots of Polygonum multiflorum Thunb. Zhongcaoyao 2006, 37:1311-1313.

27. Zhang $Z G$, Lu TS, Yao QQ: Study on the un-anthraquinone components of the roots of Polygonum multiflorum Thunb. Zhongguo Zhong Yao Za Zhi 2006, 31:1027-1029.

28. Yoshizaki M, Fujino H, Arise A, Ohmura K, Arisawa M, Morita N: Polygoacetophenoside, a new acetophenone glucoside from Polygonum multiflorum Thunb. Planta Med 1987, 53:273-275.

29. Chen $Y$, Wang M, Rosen RT, Ho CT: 2,2-Diphenyl-1-picrylhydrazyl radicalscavenging active components from Polygonum multiflorum Thunb. J Agric Food Chem 1999, 47:2226-2228.

30. Zhang ZG, Lu TS, Yao QQ: Effect of preparation on the major chemical constituents of Polygonum multiflorum. Zhongyaocai 2006, 29:1017-1019.

31. Liu ZL, Chao ZM, Liu YY, Song ZQ, Lu AP: Maillard reaction involved in the steaming process of the root of Polygonum multiflorum. Planta Med 2009, 75:84-88.

32. Jiao $Y$, Zuo Y: Ultrasonic extraction and HPLC determination of anthraquinones, aloe-emodine, emodine, rheine, chrysophanol and physcione, in roots of Polygoni multiflori. Phytochem Anal 2009, 20:272-278.

33. Zuo Y, Wang C, Lin Y, Guo J, Deng Y: Simultaneous determination of anthraquinones in radix Polygoni multiflori by capillary gas 
chromatography coupled with flame ionization and mass spectrometric detection. J Chromatogr A 2008, 1200:43-48.

34. Li BY, Hu Y, Liang YZ, Huang LF, Xu CJ, Xie PS: Spectral correlative chromatography and its application to analysis of chromatographic fingerprints of herbal medicines. J Sep Sci 2004, 27:581-588.

doi:10.1186/1749-8546-5-29

Cite this article as: Liang et al.: Comparison of raw and processed Radix Polygoni Multiflori (Heshouwu) by high performance liquid

chromatography and mass spectrometry. Chinese Medicine 2010 5:29.

Submit your next manuscript to BioMed Central and take full advantage of:

- Convenient online submission

- Thorough peer review

- No space constraints or color figure charges

- Immediate publication on acceptance

- Inclusion in PubMed, CAS, Scopus and Google Scholar

- Research which is freely available for redistribution

Submit your manuscript at www.biomedcentral.com/submit

() BioMed Central 